\title{
BMJ Open Effect of a simple intervention on hand hygiene related diseases in preschools in South Africa: research protocol for an intervention study
}

\author{
Samantha Louise Lange (D) , ${ }^{1}$ Tobias George Barnard, ${ }^{1}$ Nisha Naicker ${ }^{2,3}$
}

To cite: Lange SL, Barnard TG, Naicker N. Effect of a simple intervention on hand hygiene related diseases in preschools in South Africa: research protocol for an intervention study. BMJ Open 2019;9:e030656. doi:10.1136/ bmjopen-2019-030656

- Prepublication history for this paper is available online. To view these files, please visit the journal online (http://dx.doi. org/10.1136/bmjopen-2019030656).

Received 25 March 2019 Revised 26 November 2019 Accepted 27 November 2019

A Check for updates

(C) Author(s) (or their employer(s)) 2019. Re-use permitted under CC BY-NC. No commercial re-use. See rights and permissions. Published by BMJ.

${ }^{1}$ Water and Health Research Centre, Faculty of Health Sciences, University of Johannesburg, Auckland Park, South Africa

${ }^{2}$ Environmental Health, Faculty of Health Sciences, University of Johannesburg, Auckland Park, South Africa

${ }^{3}$ Epidemiology and Surveillance Section, National Institute for Occupational Health, National Health Laboratory Service, Johannesburg, South Africa

Correspondence to

Samantha Louise Lange; samlange18@gmail.com

\section{ABSTRACT}

Introduction Hand hygiene $(\mathrm{HH})$ related illnesses such as diarrhoea and respiratory diseases, contribute to the burden of disease and are included in the top five causes of mortality in children under 5 years in South Africa. Children attending preschools are more susceptible to these infections due to the higher number of children in preschools. $\mathrm{HH}$ interventions have shown to reduce $\mathrm{HH}$-related diseases by improving $\mathrm{HH}$ practices. In South Africa, there are no documented $\mathrm{HH}$ interventions or studies in children under 5 years. The purpose of the study is to determine whether an $\mathrm{HH}$ intervention can reduce HH-related diseases among 4-5-year-old preschool children and to improve $\mathrm{HH}$ practices in these children, their caregivers and their parents.

Methodology and analysis This is a protocol for a controlled intervention study to be conducted at preschools in Kempton Park, City of Ekurhuleni, Gauteng, South Africa. Preschools will be randomly distributed into control and experimental groups $(n=70)$. The intervention includes interactive simulation learning, educational emails and education and poster reminders obtained from the WHO and the Global Handwashing Day website. Data collection, including the intervention, will take place during the calendar year as this coincides with the school year. Data will be analysed both preintervention and postintervention in the experimental group as well as between the experimental and control group. Data collected by means of questionnaires, observations, disease registers, hygiene inspections, semi-structured interviews and hand swabs will be analysed to determine these outcomes.

Ethics and dissemination Permission has been obtained from the University of Johannesburg Ethics Committee and Ministerial Consent for Non-Therapeutic Research on Minors from the Department of Health National Ethics Research Council. Permissions for use of copyright protected materials has been obtained. Results of the study will be disseminated through peer-reviewed publications, and feedback within relevant structures through conference proceedings.

\section{INTRODUCTION}

There is a high incidence of hand hygiene $(\mathrm{HH})$ related diseases among children under 5 years in South Africa. The latest results from Statistics South Africa ${ }^{1}$ show that some of
Strengths and limitations of this study

- The success of the study lies in the potential for increased improvement of hand hygiene $(\mathrm{HH})$, particularly hand washing with soap and water.

- The intervention tools to be used are those that have been developed by the WHO and international resources used for Global Handwashing Day.

- The data collected through the disease register runs the risk of under/over reporting or misdiagnosis.

- HH behaviour is self-reported and this could result in a response bias.

- Observations of $\mathrm{HH}$ opportunities and subsequent $\mathrm{HH}$ compliance may be subject to the Hawthorne effect.

the leading causes of death for under 5 years include intestinal infectious diseases, such as diarrhoea, and respiratory illnesses, such as influenza and pneumonia. Although there has been a decline in deaths associated with these illnesses as a result of public health and basic services interventions there is still a need to improve the provision of health promotion services to help reduce the prevalence of these diseases. ${ }^{2}$

Children at preschools are more susceptible to contracting infections than those that are cared for at home. There is a concentration of children found in preschools and children are exposed to each other and their various illnesses more frequently than children who stay at home and don't come into regular contact with other children. According to the General Household Survey there were an estimated 2059000 children attending preschool in South Africa ${ }^{3}$ signifying the potential transmission of $\mathrm{HH}$ related diseases to over 2 million children if $\mathrm{HH}$ is not practiced appropriately. Gaps in preschool education or increased absenteeism have been known to result in learning difficulties in later years. Childhood behaviour such as placing 
their hands or objects into their mouths and preschool activities such as sorting and arranging toys increases the risk of hand-to-mouth contamination. ${ }^{45}$ Caregivers (teachers who are not necessarily qualified) perform duties such as helping with nose blowing, assisting in toilet routines and assisting with eating where necessary. As they normally have a few children in their care, the 'hands on' approach adopted by the care givers, makes them susceptible to transmitting diseases from one child to another if proper hygiene is not practiced. Improving $\mathrm{HH}$ among preschool children can potentially reduce HH-related diseases, thereby reducing absenteeism of children, parents and caregivers.

Proper HH is considered to be an effective measure in reducing both gastroenteritis and upper respiratory tract infections. Washing hands with soap and water is seen as an effective method for halting the spread of disease. ${ }^{67}$ Hand washing with soap has shown to reduce diarrheal disease by $23 \% .{ }^{8}$ Diarrhoeal diseases are transmitted via the faecal-oral route through contaminated surfaces and human carriers, often as a result of improper hand washing especially after using the toilet. ${ }^{9}$

The description of the common cold as a light fever accompanied by a sore throat and/or coughing and/or sneezing and/or runny nose, will be used for the study. ${ }^{10}$ The common cold is spread either directly or indirectly, or through aerosol of the secretions caused by coughing and sneezing. ${ }^{11}{ }^{12}$ Hand washing can reduce upper respiratory diseases by as much as $51 \% .^{13}$

For this study $\mathrm{HH}$ is described as washing hands with soap and water using the WHO method of hand washing. Hand washing should take place at critical times, namely before eating or touching food and after using the toilet to be considered appropriate $\mathrm{HH}$ compliance for this study.

In previous studies the implementation of $\mathrm{HH}$ interventions has shown that $\mathrm{HH}$ compliance can increase by $34 \% .{ }^{14}$ Studies of $\mathrm{HH}$ in preschools have been conducted in various countries such as Netherlands, ${ }^{15}$ Israel, ${ }^{16}$ Thailand, ${ }^{17}$ India, ${ }^{18}$ New Zealand, ${ }^{19}$ Spain $^{20}$ and Iceland ${ }^{21}$ focusing on the reduction of diseases through $\mathrm{HH}$ interventions. These studies have not been conclusive in determining a specific intervention, which will work in all areas and all scenarios, as each study made use of different interventions and measured various outcomes, such as reduction of disease or reduced absenteeism. Many of these interventions included the provision of hand sanitiser or soap or both by the researchers, as part of the intervention. ${ }^{15-21}$ Although the results showed decreases in school absenteeism and HH-related diseases there is no mention of whether the schools or communities continued to supply their own materials afterwards thereby posing the question: 'can the intervention be deemed successful if it is not sustainable?'. There are, however, studies which have shown an increased HH knowledge and behaviour change that resulted in behaviour change as well as decreased absenteeism based on interventions which did not incur additional costs after the completion of the intervention. ${ }^{14} 2223$ These interventions made use of health education sessions and interactive learning regarding hand washing and nose blowing using tools such as flip-charts, ${ }^{22}$ stories ${ }^{23}$ and a Glo-yo device with ultraviolet light functionalities ${ }^{14}$ to increase HH knowledge and decrease infections.

In a report by the Water Research Commission, South Africa $^{24}$ there were no $\mathrm{HH}$ campaigns focused on the under 5 years age group in South Africa which was identified as a concern. Applying the intervention to children, caregivers and parents will determine whether HH knowledge and behaviour has improved or not. Studies have shown that parents are not always aware of the impact of $\mathrm{HH}$ on their children's health or the importance of using soap with hand washing. ${ }^{4526}$ When comparing the results in a hygiene study, reporting among other things, the gap between knowledge and practice, it was found that although $95 \%$ of respondents agreed on the importance of hand washing before eating, only $8 \%$ actually washed hands with soap before eating. ${ }^{27}$ Furthermore, the compliance with $\mathrm{HH}$ guidelines is generally low ${ }^{28}$ indicating the need for the development of an effective HH intervention. Simulation education as a single intervention was proved by Jansson et $a l^{29}$ to be unsuccessful whereas interactive education sessions, ${ }^{14}$ hygiene surveys, ${ }^{21}$ short message service (SMS) reminders, ${ }^{30}$ the WHO HH strategy ${ }^{28}$ and posters and stickers ${ }^{15}$ have been used successfully as $\mathrm{HH}$ intervention strategies.

The aim is to present the protocol for a controlled, intervention study to determine whether a $\mathrm{HH}$ intervention can reduce $\mathrm{HH}$ related diseases among 4-5-year-old preschool children as well as improve $\mathrm{HH}$ practices in the same children, their caregivers and their parents in South Africa.

\section{Objectives}

1. To determine the prevalence of $\mathrm{HH}$ related disease episodes in children age $4-5$ years before and after the intervention. The difference in diarrhoeal and upper respiratory infection (URI) episodes before and after the intervention will be calculated.

2. To determine and describe $\mathrm{HH}$ practices and compliance of children and caregivers in the preschools and parents, both before and after the intervention. The difference in $\mathrm{HH}$ practices and compliance will be calculated. HH compliance will be determined through $\mathrm{HH}$ actions divided by the total number of $\mathrm{HH}$ opportunities.

3. Comparing the results of the data obtained preintervention and postintervention for both the control and the intervention group. Indications according to literature are that differences between the experimental group for preintervention and postintervention can show that diarrhoeal disease can be reduced by at least $23 \%{ }^{8}$ and URI decrease by at least $51 \% .{ }^{13}$ Successful $\mathrm{HH}$ behaviour change post intervention should be $>34 \% .{ }^{14}$ The comparisons of the data should fall within these parameters to determine if the intervention 


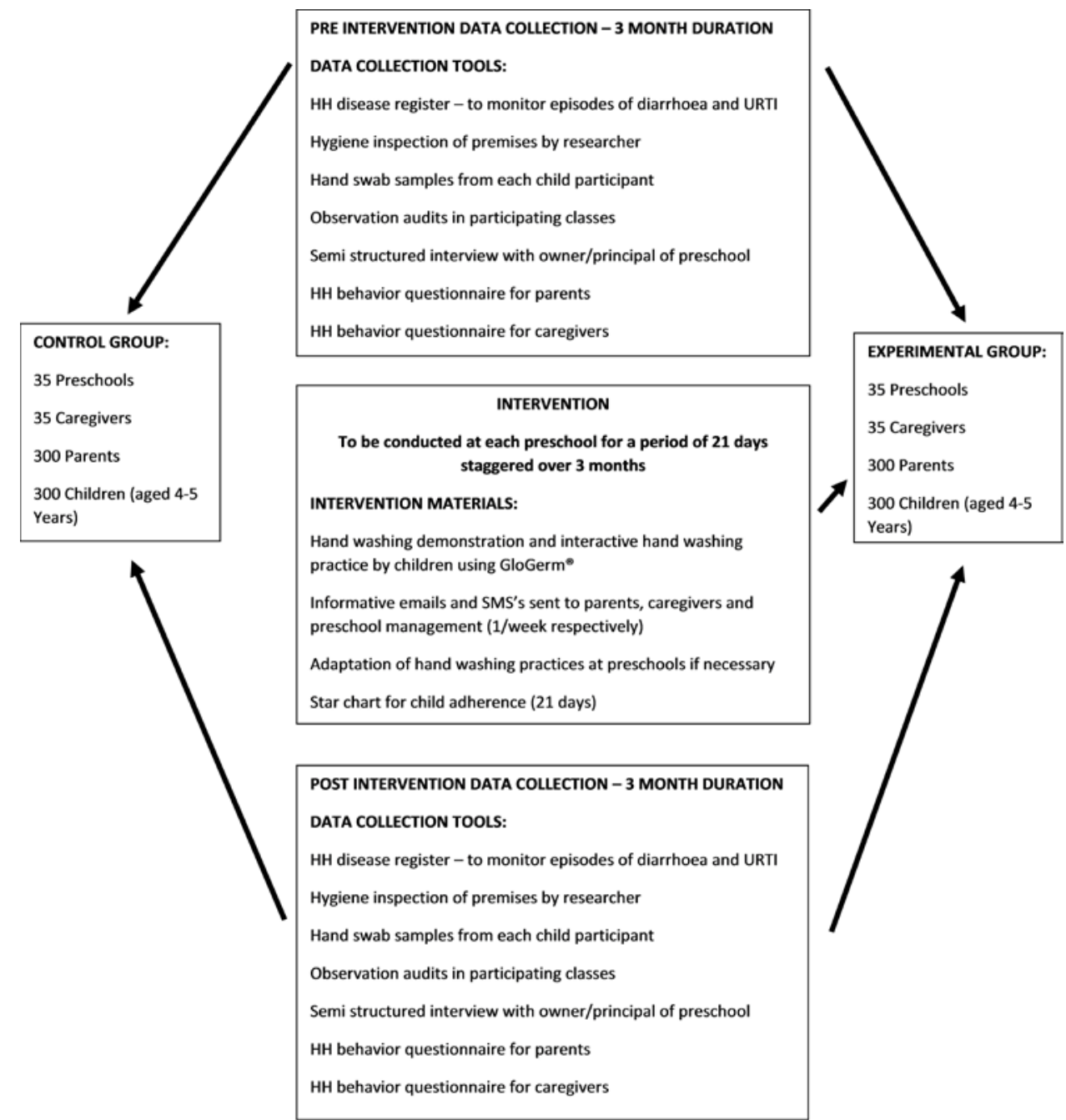

Figure 1 Conceptual framework of study. $\mathrm{HH}$, hand hygiene; SMS, short message service.

has been successful. It is hypothesised that the intervention package will increase knowledge and positively influence $\mathrm{HH}$ behaviour. There is a dearth of information on $\mathrm{HH}$ practices and influence of $\mathrm{HH}$ campaigns in this South African population thus this study should contribute essential information in this field.

\section{METHODS AND ANALYSIS}

\section{Overview of study design}

This is a protocol for an intervention study, using quantitative and qualitative data collection and analysis methods. The study will be conducted during 2019 and 2020 with data collection taking place in the latter half of 2019 and early 2020. Data will be compared between an experimental group, exposed to an $\mathrm{HH}$ intervention, and a control group, preintervention and postintervention. The data will also be compared preintervention and postintervention in the experimental group. The research framework is described in figure 1 . The preintervention data collection will be conducted at the start of the data collection phase; the intervention phase will take approximately 3 months to implement throughout all schools and the postintervention data collection will be conducted at a three and 6-month interval after the intervention. The preintervention and postintervention data will be collected from both the experimental and control groups so that comparisons between the two may be drawn.

\section{Study site and study population}

Ekurhuleni is a metropolitan area situated in the province of Gauteng, South Africa. This area which comprises Kempton Park is one of nine cities incorporated into the City of Ekurhuleni and is located in the Northern Region. It is a mostly suburban area with a small agricultural area to the north east and a few small informal settlements integrated into the suburban areas. Kempton Park, the study site, has a population of over $170000^{31}$ with approximately 200 registered and unregistered preschools in the area. It is expected that all legislatively compliant preschools in the study area will participate in the study, either as the control group or as part of the experimental group. Due to the rigorous obstacles created by the different legislations there are only 70 preschools in the area which are presently compliant/registered. Preschools within City of Ekurhuleni are expected to comply with Ekurhuleni 
Metropolitan Municipality Public Health Bylaws promulgated on 27 November 2009; Regulations Governing General Hygiene Requirements for Food Premises, Transportation of Food and Related Matters (No. 638 of 22 June 2018) and National Environmental Health Norms And Standards For Premises And Acceptable Monitoring Standards For Environmental Health Practitioners (EHP) (No. 1229 of 24 December 2015) as well as ensuring correct zoning of the premises, all of which carry economic implications for the preschool owner.

The criteria for inclusion of preschools in the study are: (1) the preschool complies with all relevant legislation and is in possession of the applicable permits and certificates issued under the legislation mentioned; (2) the preschool has the necessary infrastructure for municipal water supply, wash hand basins, soap and toilets; (3) the preschool does not fall within the researcher's area of jurisdiction as an EHP employed within the City of Ekurhuleni. This last criteria have been included to prevent any bias or unethical conduct as the researcher is also the relevant law enforcer and EHP for the excluded area/preschools. Children participating in the study must comply with the following criteria: (1) be enrolled as a pupil at the preschool and (2) be over the age of 4 years at the start of the study.

\section{Study sample}

All 70 schools which comply with inclusion criteria, will be invited to participate. There are approximately 2000 children aged 4-5 years attending the 70 preschools. Although not all 70 schools may participate, new and existing schools obtain the correct certification daily and can be approached to replace any schools not wanting to participate. Schools will be stratified into schools with 20 or less 4-5-year-old children and those with more than 20 children aged $4-5$ years. This is because some schools have in excess of 200 children and have more than one class of at least twenty $4-5$ years old whereas other schools may only have 20 children in total, with maybe 10 children in a 4-5years old class. Studies have shown that the number of children per caregiver and per class can influence $\mathrm{HH}$ practice $^{32}$ which is why the schools will be stratified for selection so that there are equal numbers of smaller and larger schools to provide a representative sample. From this sample, preschools will be randomly distributed into the control $(n=35)$ and experimental $(n=35)$ groups. It is estimated that there are 140 caregivers for the 2000 children. All caregivers who have day-to-day interaction with the children in the sample will be included in the study. For the purpose of this study, a caregiver is defined as the person who provides care and instruction to the children while they are present at the preschool. This may be the teacher, however, not all caregivers in the preschools are qualified as teachers and therefore the generic term 'caregiver' is used.

Data collection to effect the primary outcome of reducing $\mathrm{HH}$-related diseases from disease monitoring and hand swabs will be conducted on a minimum of 300 children from the experimental group and a further 300 from the control group. For sample size calculation, as reported from previous studies, it is assumed that there will be $28 \%$ (rate ratio (RR): 0.72 ) reduction in diarrhoea with general sanitation as reported by Freeman et $a l^{33}$ and $40 \%$ (RR: 0.60) reduction in diarrhoea after hand washing intervention are implemented. ${ }^{8}$ A sample size of 600 (300 controls and 300 experimental group) from 70 school clusters will give us $88 \%$ power and type I error at 0.05 level of statistical significance to show an effect size of $12 \%$ more reduction in diarrhoea among the experimental group after intervention compared with the control group. It is doubtful that all estimated 2000 children will participate in the study, however, should there be more than the anticipated 600 children, all children enrolled in the study will be sampled. The reason for this is that some children may be absent on some of the sampling days. The participation of the children and parents in the study is for two purposes: (1) to obtain hand swabs from the children and (2) to obtain information on $\mathrm{HH}$ practices in the home environment in the form of questionnaires from the parents. Consent and encouragement to participate are described in the ethics portion of this protocol.

\section{Description of HH intervention}

The intervention which will be conducted on the experimental group (see figure 1) will take the form of interactive learning, 'simulation education and hand wash poster reminders for the children as well as educational emails and SMS reminders for the caregivers and parents.

Interactive learning: this will be conducted by the researcher and will take approximately an hour to administer to both caregivers and children. This includes a demonstration of hand washing using the WHOprescribed technique as well as checking the thoroughness of the hand washing by placing GloGerm (a lotion with fluorescent properties) on the children's hands prior to hand washing and placing the hands under an ultraviolet light both before and after hand washing. The GloGerm will be removed through correct hand washing. This intervention will be administered to all children in the class regardless of whether they are part of the study or not. Consent is not needed for this as it forms part of the health promotion activities which can be offered by City of Ekurhuleni to preschools in the area.

Information to parents: parents who are part of the study will be educated via emails and SMS's making use of the WHO guidelines for $\mathrm{HH}$, the resources available on Global Handwashing Day website and the Water Research Commission report, providing information to the parents and caregivers once a week over a 3-week period as part of the intervention. ${ }^{24} 28$

Improved $\mathrm{HH}$ facilities at preschool: preschools in the intervention group will also be encouraged to improve HH-related supplies if necessary, that is, convenient placing of soap, toilet paper and so on to improve $\mathrm{HH}$. This will be based on the results of the hygiene 
HAND WASHING FOR PRESCHOOLS - METHODOLOGY

\begin{tabular}{|c|c|c|}
\hline “Magic Box" & GloGerm ${ }^{\oplus}$ & Plastic basin $\times 2$ \\
\hline $\begin{array}{l}\text { Liquid soap } \\
\text { Stickers }\end{array}$ & Paper towels & $\mathrm{A}^{3}$ Compliance Chart \\
\hline
\end{tabular}

METHOD

Give a short talk about germs, where they are found and when to wash your hands.

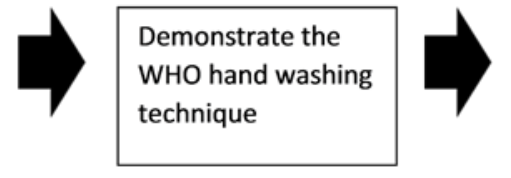

Place children's hands in magic box to see "germs"

\section{Allow each child to stick a sticker on the compliance chart and explain that they can do so each day for the next 3 weeks if they wash their hands properly}
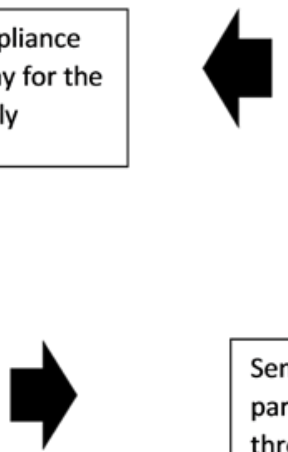

Place children's hands in "Magic box" to see clean hands

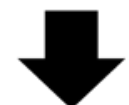

Supervise children in washing hands

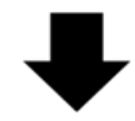

Obtain parents and caregivers contact details

Figure 2 Methodology for hand hygiene intervention.

Send informative information and videos to parents and caregivers once a week for the next three weeks inspections conducted prior to the intervention. A hygiene inspection will also be conducted postintervention to ensure that the supply suggestions were implemented.

The methodology and materials needed for the intervention can be seen in figure 2 .

As the study will make use of existing intervention materials used by the WHO and Global Handwashing Day, there can be no influence over the effectiveness of the materials themselves as they have already been tested and validated worldwide. There are no previously documented campaigns focused on the under-five age group in South Africa, ${ }^{24}$ therefore, the implementation of a pilot project will assist in fine-tuning both data collection and intervention activities. The pilot project will be conducted in 12 schools in the area which will be randomly selected. Any children who comply with the study criteria, will be included in the pilot study. Working on the assumption of an average of 30 possible candidate children per school this should provide a sufficiently high numerical sample to test both the data collection tools and the intervention methods. Schools in the pilot study will not be included in the main study, however, results from the pilot will be published as an addendum to the main study.

\section{Data collection}

Collection of data from both the control and experimental group will be conducted prior to and within a 3-month period after the implementation, using the following tools:

Hand Hygiene Disease register: in this study HH-related diseases have been restricted to diarrhoea, described as three or more loose or liquid stools per day ${ }^{34}$ and the common cold. ${ }^{10}$ Caregivers will record the occurrence of these diseases in the children in the class over a 6-month period, starting at least 2 months before the intervention. The caregivers will be provided with a disease register where they will note each child's absence, the reason for the absence and the date on which the child returned to school. This information will be obtained by the caregiver from the parent on the child's return to school. Should the child become sick at school and remain in school, this will also be recorded by the caregiver. Because ethical considerations require that study participants that is, the child remain anonymous, all children will be recorded, regardless of whether they are part of the study or not. The researcher will then assign the children participating in the study to the data set. In South Africa, most preschools only close for school holidays in December as parents do not have other means of caring for their children when they are at 
work, meaning that most preschool children remain at the preschool daily, for the entire year. It is possible that some children may be absent from school as a result of vacations taken with the family and therefore some data may be lost in this way. However, caregivers will be instructed to try and obtain as much information from the parents regarding the health of the children when they are absent from school.

Hygiene Inspection of Premises: a hygiene inspection based on City of Ekurhuleni Environmental Health division inspection forms will be conducted prior to and after the intervention. The inspection includes determining the presence of soap, toilet paper, hand sanitisers and other HH related equipment in the preschools. This hygiene inspection will be conducted by the researcher who is a qualified EHP.

Hand swab samples: swab samples will be collected from the children who have consented to be part of the study. These samples will be collected at least a month prior to the intervention and at least 1 month after the intervention. Samples will be collected by the researcher from the dominant hand of each child participating in the study using the COPAN Transystem culture swab transport system with Amies media without Charcoal plastic applicator with rayon tip. The dominant hand has shown to have increased bacterial loads. ${ }^{35}{ }^{36}$ The swab will be moistened with sterile phosphate buffered saline and streaked across the hand of the children, including between the fingers. The cotton part of the swabs will be placed in $10 \mathrm{~mL}$ peptone water and used for the pour plate method by mixing $1 \mathrm{~mL}$ sample with $15 \mathrm{~mL}$ Plate Count Agar and incubated for 72 hours at $30^{\circ} \mathrm{C}$ as described by the South African National Standard 5763:2006. Samples will also be plated onto 5\% Sheep blood agar (National Health Laboratory Services), MacConkey agar (Oxoid) and HiChrome agar (Sigma) to study the presence of specific pathogens and Escherichia coli (as indicator of faecal pollution). Plates will be incubated at $37^{\circ} \mathrm{C}$ for $24-48$ hours and growth monitored and recorded after 24 and 48 hours of growth.

Observation audits: a 20-min observation of caregivers and children will be conducted by the researcher, where $\mathrm{HH}$ opportunities will be reported on an observation form. The observation will take place while the children are in the classroom during their class work activities. These activities normally take place in the mornings, after breakfast and before mid-morning snacks and outside play time, depending on the specific routines of each preschool. The opportunities have been described by $\mathrm{WHO}^{37} 38$ and Richardus $e t a l^{15}$ and include opportunities such as caregivers washing hands before administering medication and children washing hands before placing fingers in the mouth or after placing fingers in nose. The observation will be conducted preintervention and postintervention in order to assist in determining the success of the intervention through observing compliance with $\mathrm{HH}$ opportunities. Observations may be subject to the Hawthorne-effect ${ }^{39}$ especially in the control group where the intervention will not be conducted, however, the data collected from the $\mathrm{HH}$ behaviour questionnaire and the hand swabs both before and a few months later may indicate whether the changes are due to the observation or not.

Semi-structured interviews: this is a multilevel study involving preschools, caregivers, parents and children. It is necessary to determine whether or not the perceptions and attitude of the owner/principal of the school plays a role in the $\mathrm{HH}$ practices of the caregivers and children. A recorded, semi-structured interview with open-ended questions will be conducted with the owner/principal in order to understand their management style and day-to-day running of the school as well as their communication strategies. Some of the questions will include 'How long have you been at the school?', 'What percentage of the budget is spent on cleaning materials?' and 'Do you think children waste toilet paper and soap?'. The audio recordings will be transcribed, coded and frequencies will be determined for the responses.

Knowledge and practices questionnaire: a structured questionnaire will be self-administered by the caregiver regarding the knowledge and practices within the preschool setting. A questionnaire with additional questions regarding the intervention will be self-administered postintervention. A similar questionnaire will be selfadministered by parents of participating children interrogating $\mathrm{HH}$ practices within the household preintervention and postintervention in both the experimental and control groups. These questionnaires will be sent to each participating parent and caregiver by hand in an envelope and will be returned to the school for collection after 2 weeks. The questionnaires will be administered 3 months preintervention and 3 and 6 months postintervention. HH behaviour is self-reported and this could result in a response bias, however, these results will be cross-checked with the $\mathrm{HH}$ observation and the hand swabs. Sample questions for the parents and caregiver are found in tables 1 and 2, respectively. The answers to the questions are given in a 7-point Likert scale ranging from 'Never' $=0$ to 'Always' $=6$. For analysis purposes, answers in Block 0 and 1 will be grouped together as 'Never', Block 2, 3 and 4 as 'Sometimes' and Block 5 and 6 as 'Always'. This 7-point Likert scale was used to provide respondents with an opportunity to provide the most accurate answer

Table 1 Sample questions from household questionnaire for parents

\begin{tabular}{lllllllll}
\hline & Never & & $\begin{array}{c}\text { Some } \\
\text { times }\end{array}$ & & Always \\
\hline $\begin{array}{l}\text { My children wash } \\
\text { their hands before } \\
\text { eating anything }\end{array}$ & 0 & 1 & 2 & 3 & 4 & 5 & 6 \\
$\begin{array}{l}\text { I wash my hands } \\
\text { before I eat anything }\end{array}$ & 0 & 1 & 2 & 3 & 4 & 5 & 6 \\
$\begin{array}{l}\text { I throw a tissue away } \\
\text { once I have used it } \\
\text { and don't keep it in } \\
\text { my hand }\end{array}$ & 0 & 1 & 2 & 3 & 4 & 5 & 6 \\
\hline
\end{tabular}


Table 2 Sample questions from caregiver questionnaire

\begin{tabular}{|c|c|c|c|c|c|c|c|}
\hline & Never & & & $\begin{array}{l}\text { Some } \\
\text { times }\end{array}$ & & & Always \\
\hline $\begin{array}{l}\text { Children in my class } \\
\text { have become sick } \\
\text { because I didn't wash } \\
\text { my hands correctly }\end{array}$ & 0 & 1 & 2 & 3 & 4 & 5 & 6 \\
\hline $\begin{array}{l}\text { The children in my } \\
\text { class wash their } \\
\text { hands after using the } \\
\text { bathroom }\end{array}$ & 0 & 1 & 2 & 3 & 4 & 5 & 6 \\
\hline $\begin{array}{l}\text { There is soap and } \\
\text { paper towels available } \\
\text { for the children in my } \\
\text { class to wash their } \\
\text { hands with }\end{array}$ & 0 & 1 & 2 & 3 & 4 & 5 & 6 \\
\hline
\end{tabular}

without the possibility of them feeling that they may be judged by their actions.

\section{Analysis}

\section{Data management}

All study data will be manually entered into IBM SPSS Statistics V.25. All data will be double-entered by the researcher into both SPSS and an Excel spreadsheet to ensure accuracy. Data will be inspected for duplicates and any obvious discrepancies through simple sorting and filtering on Excel. Missing values will be checked. Confidentiality and privacy of all study participants will be ensured by removing all identifiers such as names of the participants and schools.

\section{Descriptive analysis}

A descriptive analysis of all data collected preintervention and postintervention will be calculated. For continuous data, summary measures consisting of means, SD, medians and IQR and the minimum and maximum values will be documented. The mean number of times diarrhoea and respiratory symptoms are reported (occurrence of the disease) in study participants both before, during and after the intervention in both the experimental and control groups will be compared. Categorical data will be presented as frequencies and percentages. The qualitative data obtained through the semi-structured interviews will transcribed and similar answers grouped together and given a quantitative value which can then also be entered into SPSS for further analysis to determine similarities and trends.

\section{Inferential analysis}

In order to compare the rates of occurrence of disease preintervention and postintervention a Poisson regression analysis will be conducted. Thus, this method will allow evaluation of the effectiveness of the intervention. In addition, the differences between the control and the intervention groups will be calculated. Normality will be examined by testing using the Shapiro Wilk test in SPSS.

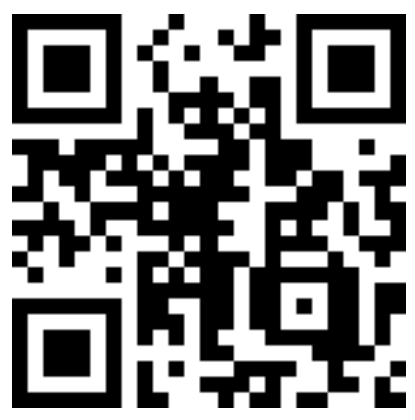

Figure 3 Quick response code for explanatory video.

\section{PATIENT AND PUBLIC INVOLVEMENT}

Patients or public were not directly in the development of the study. However, during the semi-structured interview with the owners of preschools their experience regarding an effective way to communicate with parents and children in the schools will be explored. This can then be communicated in the study findings. A leaflet with the findings and results will be developed in consultation with respondents for dissemination.

\section{ETHICS AND DISSEMINATION}

We attest that we have obtained appropriate permissions and paid any required fees for use of copyright protected materials. This study will include children aged 4-5 years therefore care has been taken to develop an information and assent letter that children can understand making use of pictures. Consent will be given by the parent to allow the child to participate in the study and the child will agree to the participation by placing a sticker on the form. The University of Johannesburg Ethics Committee has given permission to make use of local community Facebook groups to create awareness of the study and encourage participation. To facilitate the consent process, an explanatory video has been developed. A quick response code has been generated as seen in figure 3 and a video link (http://bit.ly/HHconsent) has been uploaded to University of Johannesburg's BlUJoy Youtube channel. Posters have also been placed in participating schools to encourage participation.

The collection of personal information such as email and telephone numbers will be conducted under Sections 13, 14 and 18 of the Protection of Personal Information Act. ${ }^{40}$ Hard copies of data collection tools will be stored in the researcher's secure building for a minimum of 5 years. All identifying information will be removed from data sets before being electronically stored in a secure cloud-based storage facility. The participants retain the right to withdraw from the study at any time of the study process. Results of the study will be disseminated through peer reviewed publications and feedback within the City of Ekurhuleni and other government structures in the form of conference presentations. As part of the patient and public involvement a leaflet with the findings and results will be disseminated to participants of the study. 
Contributors SLL, TB and NN designed the study and wrote the paper with input from all three authors.

Funding The authors have not declared a specific grant for this research from any funding agency in the public, commercial or not-for-profit sectors.

Competing interests None declared.

Patient consent for publication Not required.

Ethics approval Permission has been obtained from the University of Johannesburg Ethics Committee (Approval No. REC-01-165-2017) as well as Ministerial Consent for Non-Therapeutic Research on Minors for Department of Health National Ethics Research Council (Approval No.GP 201804 002).

Provenance and peer review Not commissioned; externally peer reviewed.

Open access This is an open access article distributed in accordance with the Creative Commons Attribution Non Commercial (CC BY-NC 4.0) license, which permits others to distribute, remix, adapt, build upon this work non-commercially, and license their derivative works on different terms, provided the original work is properly cited, appropriate credit is given, any changes made indicated, and the use is non-commercial. See: http://creativecommons.org/licenses/by-nc/4.0/.

\section{ORCID iD}

Samantha Louise Lange http://orcid.org/0000-0002-3435-0290

\section{REFERENCES}

1 Statistics South Africa. Mortality and causes of death in South Africa, 2013: Findings from death notification. Stat release [Internet], 2015. Available: http://www.statssa.gov.za/Publications/P03093/ P030932010.pdf\%5Cnhttp://www.statssa.gov.za/Publications/ P03093/P030932009.pdf

2 Bamford L, Barron P, Kauchali S, et al. Inpatient case fatality rates improvements in children under 5: diarrhoeal disease pneumonia and severe acute malnutrition. South African Med J 2018;108:s33-7.

3 StasSA Enrolment E. Education Series Volume III : Vol. III. Statistics South Africa Report No. 92-01-03; 2016.

4 Ngure FM, Majo F, Mbuya MNN, et al. Formative research on hygiene behaviors and geophagy among infants and young children and implications of exposure to fecal bacteria. Am J Trop Med Hyg 2013;89:709-16.

5 Osei AM. The use of Pre-Reading activities in reading skills achievement in preschool education. European J Ed Res 2016;5:35-42.

6 Greenland K, Cairncross S, Cumming O, et al. Editorial: can we afford to overlook hand hygiene again? Trop Med Int Heal 2013;18:246-9.

7 Curtis V, Cairncross S. Effect of washing hands with soap on diarrhoea risk in the community: a systematic review. Lancet Infect Dis 2003;3:275-81.

8 Prüss-Ustün A, Bartram J, Clasen T, et al. Burden of disease from inadequate water, sanitation and hygiene in low- and middle-income settings: a retrospective analysis of data from 145 countries. Trop Med Int Health 2014;19:894-905.

9 Croxen MA, Law RJ, Scholz R, et al. Recent advances in understanding enteric pathogenic Escherichia coli. Clin Microbiol Rev 2013;26:822-80.

10 Cotton MF, Hendson W, Maartens G, et al. Updated recommendations for the management of upper respiratory tract infections in South Africa. South African Med J 2015;105.

11 Allan GM, Arroll B. Prevention and treatment of the common cold: making sense of the evidence. Can Med Assoc J 2014;186:190-9 http:// www.embase.com/search/results?subaction=viewrecord\&from=export\& id=L372425794\%0Ahttp://www.cmaj.ca/content/186/3/190.full.pdf+ html\%0Ahttp://dx.doi.org/10.1503/cmaj.121442\%0Ahttp://bvgcsalud. c17.net/openurl?sid=EMBASE\&issn $=08203946 \&$ id $=10.1503 \% 2 \mathrm{Fc}$

12 Bloomfield SF, Aiello AE, Cookson B, et al. The effectiveness of hand hygiene procedures in reducing the risks of infections in home and community settings including handwashing and alcohol-based hand sanitizers. Am J Infect Control 2007:35:S27-64.

13 Aiello AE, Perez V, Coulborn RM, et al. Facemasks, hand hygiene, and influenza among young adults: a randomized intervention trial. PLoS One 2012;7:e29744.

14 Metcalfe J, Hardie KR, Segal Jl, et al. Impact of an educational intervention upon the hand hygiene compliance of children. $J$ Hosp Infect . 2013;85:220-5.

15 Richardus JH, Voeten HA, Vlaar N, et al. A hand hygiene intervention to decrease infections among children attending day care centers: design of a cluster randomized controlled trial. BMC Infect Dis 2013;13.
16 Manor O, Meir M, Rosen L, et al. Enabling hygienic behavior among preschoolers: improving environmental conditions through a multifaceted intervention. Am J Heal Promot 2011;25:248-56.

17 Pandejpong D, Danchaivijitr S, Vanprapa N, et al. Appropriate timeinterval application of alcohol hand gel on reducing influenza-like illness among preschool children: a randomized, controlled trial. Am $J$ Infect Control 2012;40:507-11.

18 Nicholson JA, Naeeni M, Hoptroff M, et al. An investigation of the effects of a hand washing intervention on health outcomes and school absence using a randomised trial in Indian urban communities. Trop Med Int Health 2014;19:284-92.

19 Priest P, McKenzie JE, Poore MR, et al. Hand sanitisers for reducing illness absences in primary school children in New Zealand: a cluster randomised controlled trial study protocol. Trials 2010;11:1-11.

20 Azor-Martinez E, Yui-Hifume R, Muñoz-Vico FJ, et al. Effectiveness of a hand hygiene program at child care centers: a cluster randomized trial. Pediatrics 2018;142:e20181245

21 Gudnason T, Hrafnkelsson B, Laxdal B, et al. Does hygiene intervention at day care centres reduce infectious illnesses in children? an intervention cohort study. Scand J Infect Dis 2013;45:397-403.

22 Shrestha A, Angolkar M. Improving hand washing among school children: an educational intervention in South India. Al Ameen J Med Sci 2015;08:81-5.

23 Croghan E. Preventing sickness absence from early years education. Br J Sch Nurs 2008;3:230-3.

24 Wilkinson M, Toit A, Mashimbye D. Development of a framework for hand hygiene assessment 2012.

25 Mohamed NA, Zulkifli Amin NN, Ramli S, et al. Attitudes and practices of hand hygiene among parents of preschool children. $J$ Sci Innov Res [Internet] 2016;5:1-6 www.jsirjournal.com

26 Lam W, Dawson A, Fowler C. The health literacy of Hong Kong Chinese parents with preschool children in seasonal influenza prevention: a multiple case study at household level. PLoS One 2015; 10:e0143844-19.

27 Rabbi SE, Dey NC. Exploring the gap between hand washing knowledge and practices in Bangladesh: a cross-sectional comparative study. BMC Public Health 2013;13:89.

28 Allegranzi B, Gayet-Ageron A, Damani N, et al. Global implementation of who's multimodal strategy for improvement of hand hygiene: a quasi-experimental study. Lancet Infect Dis 2013;13:843-51.

29 Jansson MM, Syrjälä HP, Ohtonen PP, et al. Simulation education as a single intervention does not improve hand hygiene practices: a randomized controlled follow-up study. Am J Infect Control . 2016:44:625-30.

30 Déglise C, Suggs LS, Odermatt P. Short message service (SMS) applications for disease prevention in developing countries. J Med Internet Res 2012;14:e3.

31 City Population website [Internet]. Available: http://www. citypopulation.de/php/southafrica-ekurhuleni.php? cityid=797006

32 Zomer TP, Erasmus V, van Beeck EF, et al. Hand hygiene compliance and environmental determinants in child day care centers: an observational study. Am J Infect Control . 2013;41:497-502.

33 Freeman MC, Stocks ME, Cumming O, et al. Systematic review: hygiene and health: systematic review of handwashing practices worldwide and update of health effects. Trop Med Int Health 2014;19:906-16.

34 World Health Organisation. Who on hand hygiene in health care first global patient safety challenge clean care is safer care. World Heal Organ 2017;30.

35 Edmonds-Wilson SL, Nurinova NI, Zapka CA, et al. Review of human hand microbiome research. J Dermatol Sci . 2015;80:3-12.

36 De Alwis WR, Pakirisamy P, Wai San L, et al. A study on hand contamination and hand washing practices among medical students. ISRN Public Health 2012;2012:1-5.

37 Sax H, Allegranzi B, Chraïti M-N, et al. The world Health organization hand hygiene observation method. Am J Infect Control 2009;37:827-34.

38 World Health Organisation. Hand Hygiene observation - Data collection form. Available: www.who.int/gpsc/5may/moment1 observation_form.doc [Accessed 12 Mar 2019].

39 McCambridge J, Witton J, Elbourne DR. Systematic review of the Hawthorne effect: new concepts are needed to study research participation effects. J Clin Epidemiol . 2014;67:267-77.

40 Parliament of the Republic of south Africa. Protection of personal information act, 2013 ensuring protection of your personal information and effective access to information, 2013. Available: http://www.justice. gov.za/inforeg/docs/InfoRegSA-POPIA-act2013-004.pdf 